\title{
DE FORA ADENTRO: UMA EXPERIÊNCIA DE PERTENCIMENTO AFETUOSO, ENTORPECIDO, AÉREO E ENRAIZADO COM O MUNDO
}

\author{
Maurício Camargo Panella ${ }^{1}$ \\ "El ser volador, en su sueño, se \\ declara, inventor de su vuelo."
}

(Gaston Bachelard)

É da alma do artista descobrir, receber, conceber, compor, criar e compartilhar universos íntimos de entorpecimento com o mundo. Aqui quero compartilhar com vocês algumas das reflexões nascidas do Projeto De fora adentro.

De Fora adentro tem seu lançamento, como Mostra aberta ao público, em julho de 2010, na $62^{\circ}$ Reunião da SBPC-Ciências do Mar- realizada na Cidade do Natal- Rio Grande do Norte. O projeto até o presente momento é composto por cinco produtos oriundos de dois propósitos centrais: difundir resultados e conteúdos científicos e promover uma experiência de educação patrimonial utilizando linguagens poéticas. Busca por esta via proporcionar ao público um contato mais lúdico com os conteúdos científicos contemporâneos produzidos pelas tecnologias de ponta. Refiro-me aqui às imagens capturadas por satélites, algumas delas acessadas por um público seleto no Google Earth.

De fora adentro tem como principal produto, uma instalação, um objeto de experimento, uma imagem aérea da cidade de Natal impressa em banner, medindo 23 metros de comprimento por 16 de largura. São quase 350 metros por onde as pessoas podem reconhecer todas as casas, ruas, avenidas, praias, reservas naturais e rios que fazem a geografia natural e urbanística da cidade. Esta imagem impressa é um convite para que as pessoas caminhem descalças com cuidado, carinho e atenção pela cidade. É um convite a um passeio de reconhecimento aéreo da Cidade do Natal.

O segundo e o terceiro produto até agora concebidos são duas obras audiovisuais. Uma delas é o documentário De fora adentro, de 21 minutos, que mostra a interatividade das pessoas com a obra, e apresenta alguns depoimentos do público visitante. O outro é um curta-metragem, De fora adentro- no ritmo da cidade, de 6 minutos, com imagens e sons da cidade do Natal. O quarto produto é a exposição

\footnotetext{
${ }^{1}$ Universidade Federal do Rio Grande do Norte, Brasil.
} 
fotográfica, Devaneio Costurado, com imagens sobre a interatividade do público com a obra. E o quinto produto é o espetáculo multimídia Cartografia dos Sentidos.

Neste artigo tratarei de relacionar algumas reflexões que nasceram durante e após o lançamento da Mostra na $62^{\circ}$ SBPC. São reflexões nascidas pelo encontro entre alguns conceitos desenvolvidos por Gaston Bachelard no livro $O$ ar e os Sonhos com a interatividade e os depoimentos dos visitantes.

Estamos no Projeto De fora adentro. Quer-se sobrevoar nosso lugar para melhor se aterrissar nele. Quer-se distanciar, afastar-se de compreensões fragmentadas. Quer-se experimentar algumas sensações que Bachelard (1958) nomeia como de entorpecimento, de vertigem, de elasticidade, ingravidez e leveza com o mundo e com as relações que nele se instauram.

Um visitante entra em De fora adentro e pergunto:

- Como o senhor se sente ao caminhar sobre a imagem?

- "Isso aqui é como se você estivesse num helicóptero procurando saber onde é... Sinto-me perdido sobre a cidade de Natal e a região metropolitana”.

Criemos asas em nossos tornozelos. Teçamos nossos tapetes voadores. "Tudo nos leva em direção as alturas, para a luz, para o céu, já que voamos intimamente, já que há vôo em nós." (Bachelard, 1958: 54). Criemos nossas asas assim como muitas outras pessoas criaram em tantos outros tempos e em tantos outros lugares. Refiro-me especificamente aos infinitos potenciais oferecidos por meio da imaginação dinâmica aérea, os quais Bachelard desenvolve para fundamentar alguns de seus pensamentos e intuições.

Ao perguntar aos visitantes da Mostra como se sentiam ao caminhar sobre a imagem ampliada, algumas pessoas se mostram maravilhadas ao se sentirem gigantes.

- "Me senti gigante. Porque nunca vi de cima. A cidade é enorme e você olha um canto assim bem pequenininho...." (alunos do ensino fundamental). 


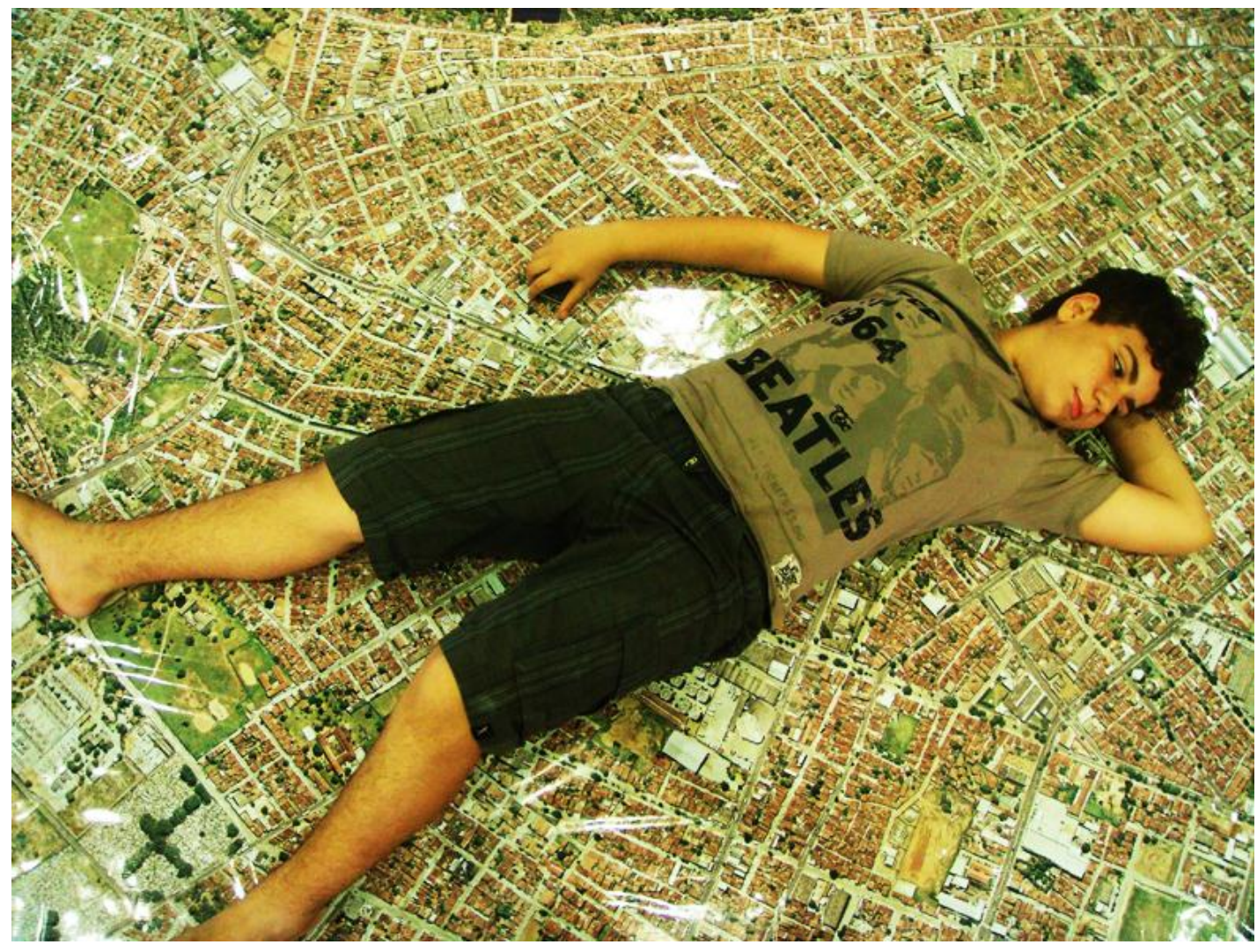

A composição das imagens aéreas da Cidade do Natal ao serem ampliadas em grande dimensão nos torna gigantes. "Ou dito de outro modo, as imagens poéticas são operações do espírito humano na medida em que nos deixam leves, nos levantam ou nos elevam." (Bachelard, 1958: 57). Tarefa importante para adentrar neste estado perceptivo de engrandecimento e leveza é erguer-nos da dimensão horizontal. Num passado muito remoto já nos havíamos erguido. Mas agora nosso eixo de verticalidade é em direção à levitação. Agora nos cabe elevar. Agora nos cabe despertar sentidos adormecidos e acomodados. Cabe-nos respirar. Erguer-nos e assumirmos a monitoria da liberdade. Ao tornarmo-nos gigantes e caminharmos pelo mundo alcançamos a sabedoria das elevadas alturas e assim aterrissamos melhor nele.

Um senhor de Uberlândia, Minas Gerais, que passeava pela Mostra De fora adentro, declara descobrindo a cidade de outra forma.

- “O interesse que eu vejo aqui é a parte macroscópica passando para a parte microscópica. Por exemplo, eu estou razoavelmente acostumado a usar o Google, o 
mapa do Google. Mas não dá para ter toda essa visão que tem aqui. Eu acho que é muito importante a gente se localizar não só no lugar onde você está, mas você se localizar como pessoa. Então, por exemplo, esta é a terceira vez que eu venho para Natal, conheço muito pouco Natal. Eu não tinha essa visão toda de espaço. Então, por exemplo, ela (filha dele) me perguntou sobre aquele traço ali. Tem um rio. Ela não tinha a visão que não era só mar".

A arte é nosso artifício, nossa artimanha para lograr o estado de levitação e ascensão. As imagens digitalizadas agora não estão soltas como encontradas no Google Earth, agora elas estão unidas e bastante ampliadas. Podemos não somente vê-las num monitor em posição vertical. Agora nós é que nos colocamos em posição vertical perante elas. Porque somos maiores que elas. Não podemos esquecer que somos maiores que a técnica que as capturou. Elas são tão grandes que podemos caminhar sobre elas. "O labor do poeta é ativar ligeiramente as imagens para certificar-se de que o espírito humano atua humanamente, para certificar-se que são imagens humanas que humanizam forças do cosmos. Então se entra na cosmologia do humano." (Bachelard, 1958: 58).

O Projeto De fora adentro possibilita-nos estar no extremo sul da cidade e ver o extremo norte, permite-nos ver os vários braços de rios. Deixa-nos ver a vegetação que cobre o corpo da cidade. Escancara-nos como o crescimento urbano se estende pelas quatro direções. De fora adentro demonstra de modo concreto, literalmente concreto, a atuação humana destrutiva com a diversidade da vida biológica.

O mesmo visitante que ao entrar em De fora adentro e se sentia perdido, ao sair manifesta outra impressão:

- "Sinto-me espetacular. Muito emocionado".

Então eu pergunto o que mudava no modo como ele via a cidade. E ele responde:

"O que muda? Na verdade a gente fica preocupado com o futuro. Porque a gente vê muito verde aqui, hoje. O que a especulação imobiliária está fazendo está acabando com o verde. E para o futuro não se vislumbra coisas boas para nossos herdeiros. Era para a gente combater. Ainda tem muito verde, mas já teve muito mais."

Parece que, ao elevar-nos, nossa visão é ampliada, modificada e deste modo acessamos uma dimensão contemplativa existente em nós que subverte uma das leis mais rigorosas impostas para nossa existência: a lei da Gravidade. "A lei da Gravidade é uma lei psíquica diretamente humana. Está em nós, é um destino que há que vencer e 
o temperamento aéreo têm, em seu encantamento, a presença da sua vitória." (Bachelard, 1958: 75).

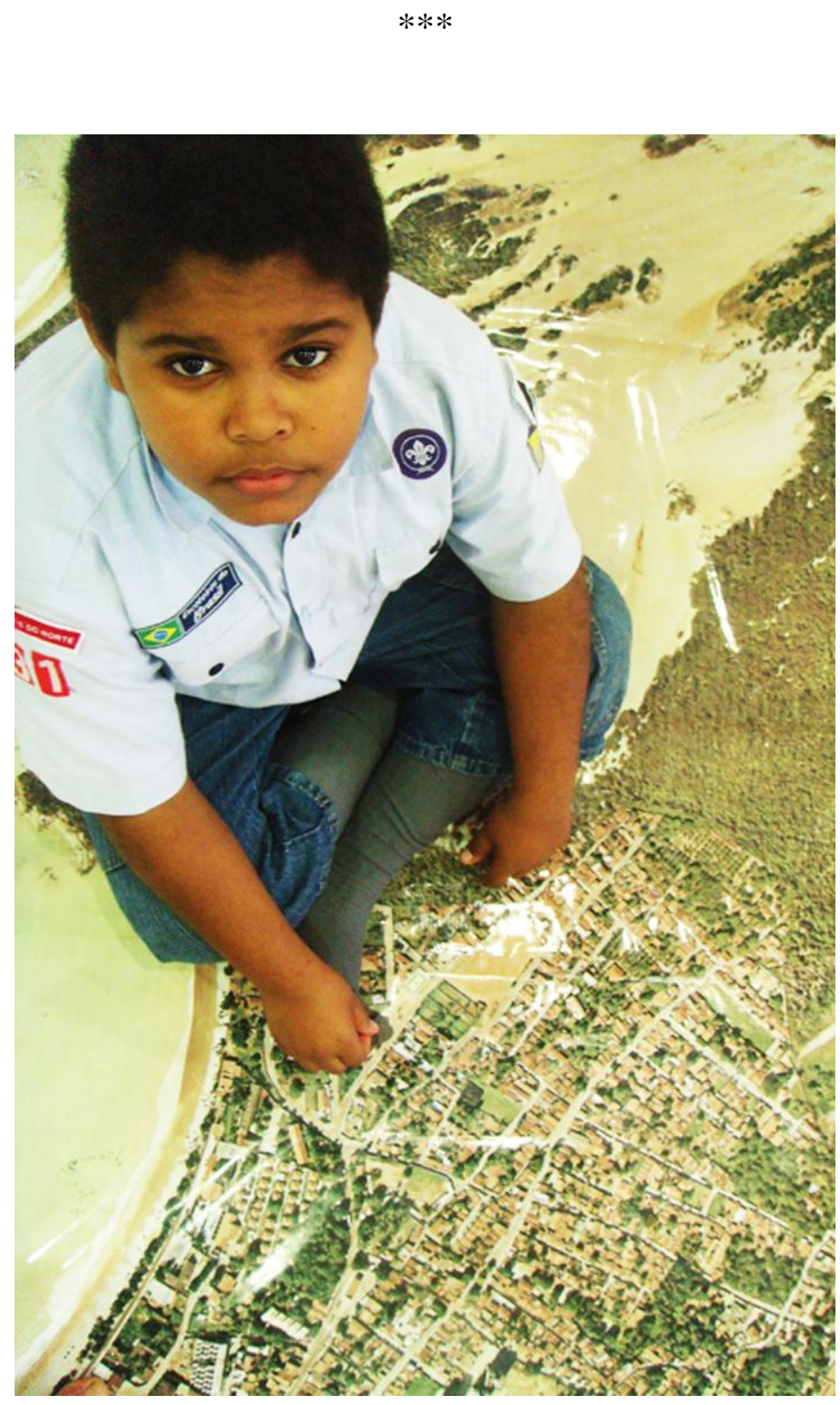

A sensação de sermos gigantes, proporcionada pela experiência na mostra $D e$ fora adentro, nos permite alcançar as alturas dos satélites. Podemos enxergar a totalidade que compõe a geografia das regiões. Podemos nos apropriar de nosso lugar, sabemos o que tem nele, de que está composto, quais seus caminhos, seus cumes, seus vales. Ocorre uma apropriação afetuosa onde se sente que nada pertence somente a uma 
criatura terrestre. Nossos gigantes nos fazem pequeninos em nossos estranhos caminhos da existência. A experiência das alturas nos enraíza. Mais alto o vôo, mais profundo é o enraizamento na Terra. Na mesma proporção. Nosso eixo de verticalidade das sensações cósmicas se aguça, se excita. Entramos em estado de entorpecimento momentâneo. Nossos sentidos ficam embriagados. E outra dimensão se abre. Nossos pés são imensos, podemos esmagar cinco ou seis casas com um só passo, ou podemos pisar com mais atenção no chão que nos acolhe. "A altura é mais que um símbolo. Aquele que a busca, que a imagina com todas as forças da imaginação, que é o motor mesmo de nosso dinamismo psíquico, reconhece que é materialmente, dinamicamente moral." (Bachelard, 1958: 81). A subida e consequiente visão das alturas promove o que Bachelard chama de movimento ascensional, movimento vertical. E instaura por isso mesmo um movimento de profundidade, de mergulho, de submersão ao mundo cosmogônico do ser, em direção a contemplação da cosmicidade e da comicidade do ser. "Quem vê longe tem a vista clara, seu rosto se ilumina." (Bachelard, 1958:74).

A verticalidade oferecida pelas alturas deforma as imagens concebidas pela horizontalidade. Dentro do mundo imaginário De fora adentro somos nós os satélites em movimento dinâmico. Todas as referências básicas de localização regeneram-se. Onde está o norte? Para onde está o sul? Para onde está o mar? Onde desemboca o rio? De onde chegam os ventos?

-"Foi legal porque eu precisei entender qual o lado do rio de lá qual o lado do rio de cá e me senti descobrindo o mundo e a minha cidade. Foi muito legal descobrir a cidade do alto." (visitante da Mostra) 


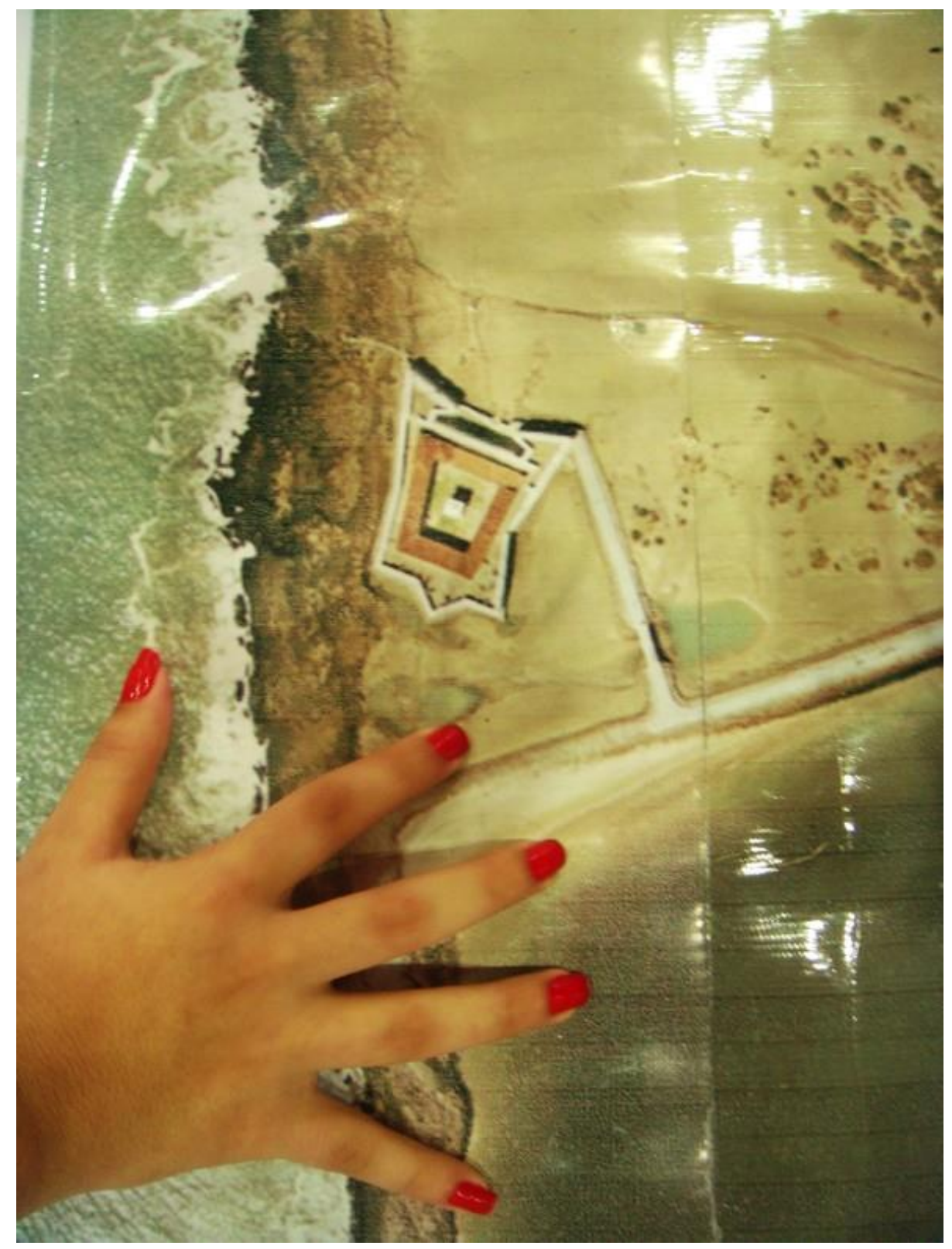

$* * *$

Então uma vez mais abrimos o presente. Outra vez mais estamos de pé. Estamos bem em cima de nossas casas. As pontas de nossos dedos tocam nossos telhados e podemos imaginar o que será servido na mesa no lanche da tarde. Podemos ajustar a posição de nossas antenas de satélite em direção a nós mesmos, agora satélites em órbita. Somos então emissores. Não mais só receptores de informações. Somos potencialmente criadores. 
Podemos nos tornar curadores. A compreensão da totalidade também nos oferece capacitação médica. Para as almas mais sensíveis, com dotes de cura, a acupuntura é ciência médica a ser desenvolvida. Muitas agulhas postas em centros errôneos podem ser retiradas. Algumas outras colocadas. E seguramente os ares fluirão de modo mais pleno entre as casas e bosques. "Imaginar é ausentar-se, é lançar-se a uma nova vida" (Bachelard, 1958: 11).

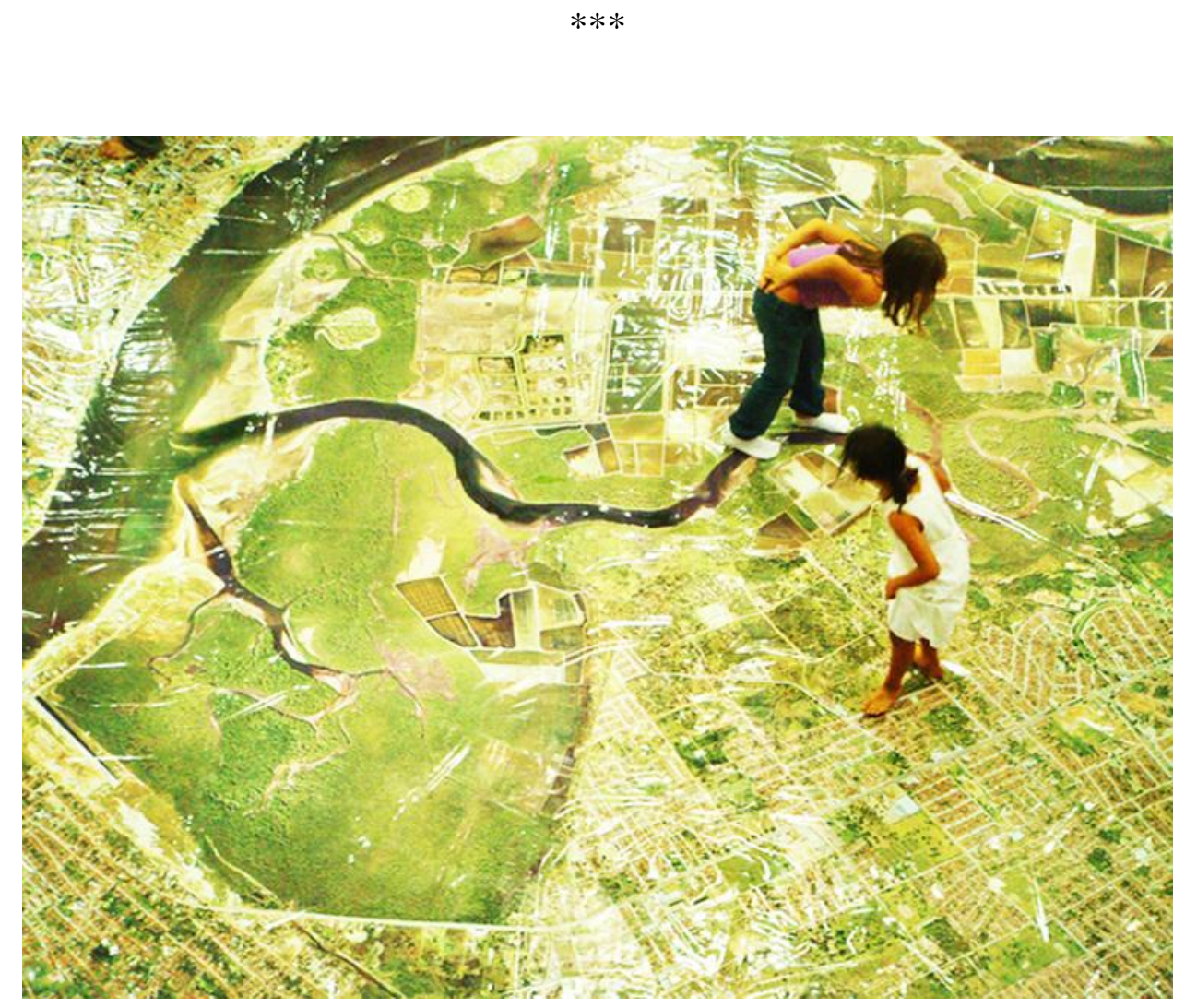

Gaston Bachelard desenvolve seu pensamento sobre a imaginação querendo compreender o trajeto empreendido entre a visão da realidade em direção aos mundos imaginários. "No reino da imaginação, a toda imanência se une uma transcendência." (Bachelard, 1958: 14). O estar no mundo das alturas muda nosso referencial rítmico. O universo que abriga as estrelas também é nosso lar. O universo se torna o jardim de nossa casa imaginária. Outra vez mais ouvimos o canto das estrelas. "Para escutar os seres do espaço infinito há que calar todos os demais ruídos da terra. É preciso 
também, - há que dizer?- esquecer todas as lições mitológicas e escolares. Então se compreende que a contemplação é essencialmente, em nós, uma potência criadora. Sentimos nascer uma vontade de contemplar, que é também uma vontade de ajudar ao movimento do que se contempla!'”(Bachelard, 1958: 66).

Quanto mais alto o vôo, maior é o enraizamento. A rítmica urbana então é sentida por sentidos unidos e percebida em descompasso com a harmonia do universo. Mas a pergunta inicial sempre é a mesma quando se pisa em De fora adentro: para onde está o norte? Pergunta que nos coloca diante de uma questão primordial: onde é o centro? "Uma verticalidade real apresenta-se no seio mesmo dos fenômenos psíquicos. Dita verticalidade não é uma metáfora vã. É um principio de ordem, uma lei de filiação, uma escala ao largo de qual se experimentam graus de uma sensibilidade especial." (Bachelard, 1958: 20).

Ao caminhar por De fora adentro se quer encontrar a própria casa, a casa das avós, a escola onde se estuda, a rota da casa que leva a mundos conhecidos. E ao entrar nesta rota percebe-se conhecendo novos caminhos, fora e dentro de nós mesmos.

- "Minha avó mora aqui na Alves Coelho com a Djalma Maranhão. Morei aqui quinze anos da minha vida. Aí agora eu me mudei e to morando aqui na rua do cemitério do bairro. Aqui nesta casa. Aqui to morando há um ano. Mas em compensação já morei aqui nesta rua, já morei aqui, detrás. Eu conheço esse bairro como a palma da minha mão. E tenho orgulho de falar dele. Aonde eu estiver eu sempre vou levar o bairro de Nova Descoberta nas minhas costas." (jovem visitante da Mostra).

O espaço exterior quando aberto de forma nova, abre também percursos novos dentro de nós mesmos. "A imaginação dinâmica é, muito exatamente, um amplificador psíquico.” (Bachelard, 1958: 24).

- "A gente vê tudo tão pequenininho que parece que a gente é grande. Que bacana!" (Moradora do Bairro do Jequi-Natal).

Quando nos libertamos das algemas da horizontalidade nossos corações também provam uma nova liberdade de sensações e compreensões sobre o mundo e sobre nós mesmos. É de verdade uma atitude paradigmática. "Quando o espírito está desta maneira um pouco preparado para a liberdade, quando se há descarregado, em certa medida, de preocupações terrestres, pode-se iniciar o exercício de ascensão imaginária." (Bachelard, 1958: 147). 
Dois jovens de Nova Descoberta manifestam-se surpresos com o estado de gigantes.

- "O que eu senti? É o poder de mandar na cidade. Não mandar...Tipo assim...Você ver a cidade do alto, parece que a cidade é pequinininha mas vendo assim é bem mais imensa do que a gente pensava."

- Meu nome é Bruno Edson, moro em Nova Descoberta. O que achei? Assim... Foi tipo ver do avião. É bem interessante porque não imaginava que o meu bairro era tão grande assim. Nessa foto ela sai bem maior.

É preciso coragem para entregar-se às novas perspectivas de mundo brotadas pelos exercícios de levitação. Ainda rastejamos pela Terra, e somos prudentes como as serpentes. No entanto somos aves de rapina e nos arriscamos a vôos e piruetas aéreas há muito tempo esperados por nosso espírito. Toda vertigem é um sobrevôo sobre nosso passado e logo nos acostumaremos aos novos estados ingravitacionais. "O homem, como homem, não pode viver horizontalmente." (Bachelard, 1958: 22).

O crescimento vertical das cidades impôs ainda mais densamente a visão limitadora da horizontalidade. Todo infinito em nós agora é desconhecido. Toda circularidade esquecida. Ao subirmos pelo eixo vertical da imaginação, ao tornarmo-nos satélites, então recuperamos a liberdade dos sentidos e das dimensões de pertencimento e cuidado com o lugar habitado. Mas o movimento inicial é justamente sairmos da Terra, para desafogar nossos espíritos enevoados por programas instaurados em nossas almas quando ainda não nos havíamos dado conta dos potenciais oferecidos pelo eixo vertical. Agora podemos libertar-nos. Toda curiosidade brota no coração do homem e este acede à percepções que possibilitam amplas reflexões sobre o que é ser monitorador e o que é ser monitorado. Toda elevação é acompanhada de serenidade. A vista que adquirimos com a gigante proporcionada em De fora adentro oferece a calma das alturas. Oferece o silêncio das esferas. De certa forma é proporcionada uma experiência analítica onde vemos desde fora de nós mesmos o que reside dentro de nós. Conseguimos ver então que não somente somos executores das formas que constituem nossos cotidianos, mas que somos determinadores do destino mesmo de nossas vidas.

- “Com relação às pessoas que passaram por aqui... É a dimensão de nossa cidade, como elas saem impressionadas, saem maravilhadas em ver a casinha deles num meio tão grande. Achar a casa dos parentes, amigos. Tudo isso. As pessoas saem com outra visão. Saem vendo que são um pedacinho dentro de um todo." (Monitora da Mostra De fora adentro). 
O sobrevôo proporcionado por De fora adentro suscita um enraizamento afetuoso. Parece que ao elevar-nos mergulhamos em nossos cotidianos. Toda a imaginação se aflora sobre nossos papéis sociais na Terra. Nossos cotidianos, nossos lugares, nossos parentes, amigos, dramas e alegrias tomam formas surreais. Existimos, ou assumimos papéis sociais? Estamos num eixo de verticalidade de favorecida posição. Podemos subir e descer do eixo sem o drama da caída. "A imaginação dinâmica une os pólos" (Bachelard, 1958: 38).

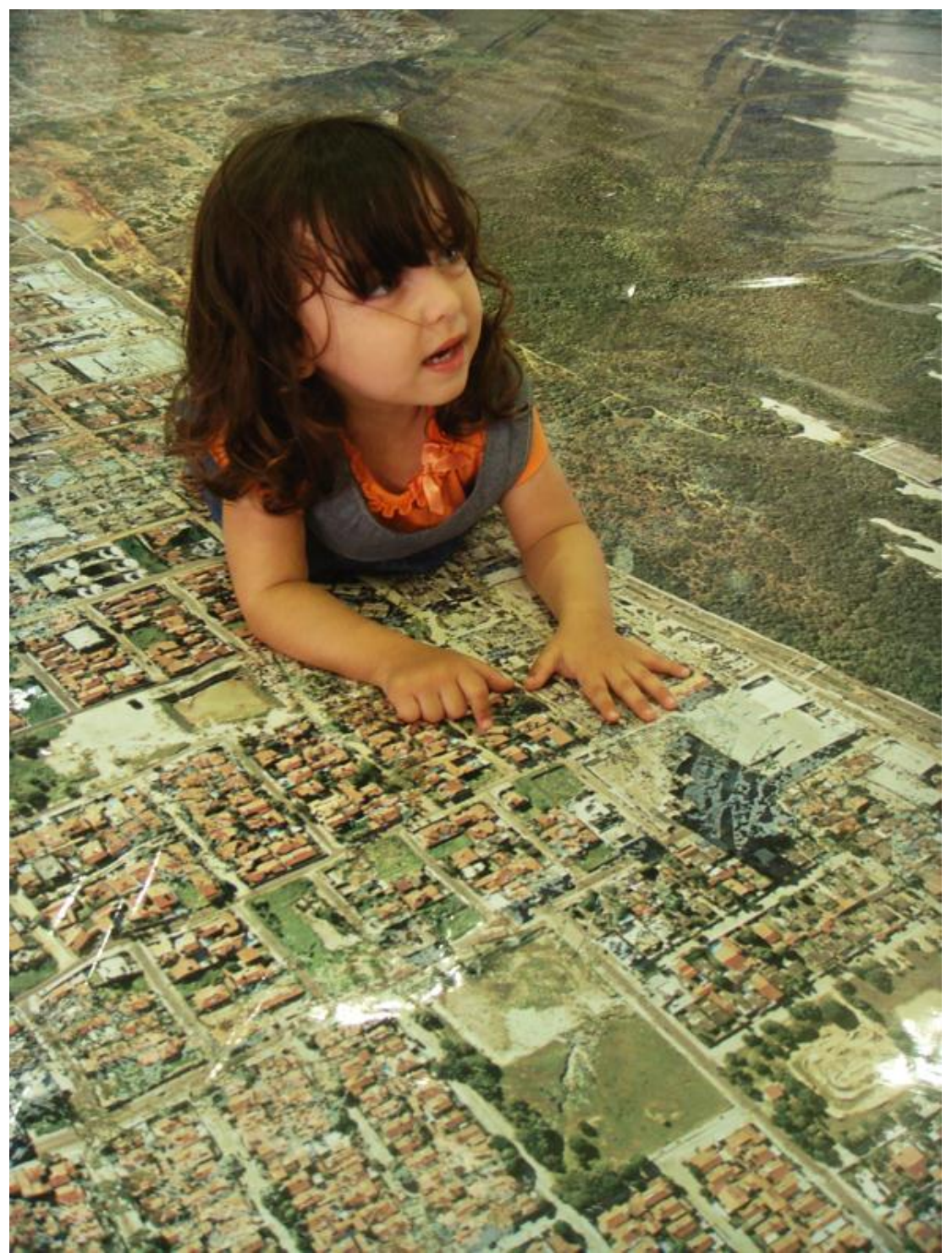


DE FORA ADENTRO...

Uma professora de geografia da Zona Norte da Cidade diz:

- “Acho importante esse trabalho porque faz com que a gente conheça melhor o espaço onde a gente trabalha, onde a gente vive, a nossa realidade. Muitos alunos não têm noção onde está qual região se encontra e, um trabalho desse, mostra na prática. Traz o aluno para colocar realmente os pés no chão. Se identificar. Então acho esse trabalho muito viável. Espero que ele também percorra outras escolas, outras áreas da cidade. Para que todas as pessoas conheçam melhor a sua cidade. Não só os espaço onde ela vive e reside, mas também a cidade como um todo, seus problemas. Porque aqui a gente vê nitidamente como o espaço vem sendo produzido. Tanto de forma benéfica como os problemas ambientais que vem agredindo a natureza que muitas vezes nem nos damos conta disso."

Toda a imaginação nascida em nossas almas nos faz gigantes minúsculos dentro de nós mesmos e o desejo de aterrissagem é na mesma proporção um desejo a se realizar. A vista que alcançamos ao nos tornarmos gigantes impulsiona a averiguação de nossas vidas minimalistas. O tão grande quer outra vez o tão pequeno. Uma paixão nasce pelo minúsculo, pelo pequeno. Somos talvez agora seres animados conhecidos por um Super Homem, como diria Nietszche. E conhecemos nossos caminhos e descaminhos desde uma perspectiva superior. Reconhecemos nossas fendas perceptivas. Agora somos seres verticais e nossas folhas e galhos são tão profundos como a doçura das raízes que voam para dentro da terra. "Faz-nos compreender que algo em nós se eleva quando alguma ação se aprofunda - e que inversamente, alguma coisa se aprofunda quando se eleva. Somos o elo entre a natureza e os Deuses, ou, para ser fiel a imaginação pura, somos o mais forte dos elos entre a terra e o ar: somos duas matérias em só ato." (Bachelard, 1958: 138).

De fora adentro promove uma sensação de falta de gravidade e entorpecimento, de afastamento e lonjura do que é terreno. Ao mesmo tempo nos aproxima afetuosamente. Somos então nada mais que pontes destes universos sempre unidos em nós mesmos. Por isso, este projeto, além de divulgar conteúdos científicos, além de promover uma experiência de entorpecimento lúdico, artístico e poético, também é uma aposta na educação patrimonial. Porque além de querer voar sobre a Terra e sobre nós mesmos, quer aterrissar em nós mesmos, em nossas belezas e desgraças. Pretende-se um reconhecimento afetuoso e crítico sobre nossos costumes, formas de viver, formas de pensar nossas atitudes e comportamentos com o que é individual, social, biológico e 
cósmico. Como diria Edgar Morin somos seres antropobiocósmicos e nossas pegadas podem ser em direção a esta consciência.

Em junho de 2012 o projeto De fora adentro foi convidado pelo Ministério da Ciência e Tecnologia e o Museu Casa da Ciência-UFRJ a compor o Pavilhão de Exposições Pop Ciência na Rio +20 , Evento Internacional sobre Sustentabilidade.

O projeto De fora adentro, com seus produtos e reflexões compõem a Tese de doutorado na Facultad de Bellas Artes da Universidad de Granada - Espanha que tem como orientador o Prof. Dr. do Departamento de Escultura (UGR) e como coorientadora a Prof. Ana Laudelina Gomes Ferreira do Departamento de Ciências Sociais da UFRN.

\section{Referências}

Bachelard, Gaston. El aire y los suenos: ensayo sobre la imaginación del movimiento. México: FCE, 1958.

Recebido em: 25/10/2012

Aprovado em: 21/12/2012 